Listening Comprehension Problems of FL Learners in a Peer Interactive, Self-Regulated Listening Task

Hatice Nur Ozcelik*, Kris Van den Branden and Elke Van Steendam Faculty of Arts, KU Leuven

This is an Accepted Manuscript of an article published by Taylor \& Francis in International Journal of Listening on 05 September 2019, available at: https://www.tandfonline.com/doi/full/10.1080/10904018.2019.1659141.

Hatice Nur Ozcelik, Faculty of Arts, KU Leuven.

Correspondence concerning this article should be addressed to Hatice Nur Ozcelik, Center for Language and Education, Blijde Inkomststraat 7, 3000 Leuven, Belgium. E-mail: haticenur.ozcelik@kuleuven.be https://orcid.org/0000-0001-9642-8973 


\begin{abstract}
It is vital to understand the listening problems students face in a foreign language (FL) classroom. In the current study, students were provided with options to identify these problems. Twenty-eight A1 level Turkish secondary school students worked in pairs and had autonomy to control the audio while listening. While dialogic exchanges illustrated articulated listening comprehension problems in a natural and observable way, self-control data enabled the researcher to observe how students chose to operate the input after encountering such difficulties. Students mostly experienced problems related to process, listener, affect, and input, followed by social- and task-related problems. The most frequent problems were mental translation, inability to chunk streams of speech and difficulty keeping pace with the delivery. In terms of self-controlling the input, students operated the audio mainly to check understanding and catch up with the speed of speech. With the help of these valuable data, the current study aims to highlight the possible benefits of peer interaction by portraying how students experienced and shared the mental, affective, and social processes involved in listening. Keywords: FL listening, listening comprehension problems, peer interaction, self-regulation, active listening
\end{abstract}




\section{Listening Comprehension Problems of FL Learners in a Peer Interactive, Self-Regulated Listening Task}

Understanding the problematic facets of listening is a crucial component of oral communication, which is the basis for the cognitive and speech aspects (i.e., receiving and interpreting messages) of language development. Because of the complexity of the processes and requirement of various types of knowledge (i.e., prior knowledge, linguistic knowledge, pragmatic knowledge, or discourse knowledge), listening is considered to be one of the most difficult skills (Field, 2009) for learners to learn, teachers to teach, and researchers to explore. Moreover, as Graham (2006, p. 178) stated "many learners see themselves as less successful in listening than in other language areas" due to the uncontrollable nature of "the speed of delivery of texts" and "the speaker's accents" (Graham, 2006, pp. 174-175). These issues, combined with student perceptions (on the difficulty and complexity of the skill; Wang, 2010) and limited experience opportunities of the FL classroom, also make it difficult for teachers to teach. Lastly, despite their awareness of the skill's centrality in the FL classroom, researchers find it difficult to explore listening comprehension since its perception process is hidden from direct observation and it is the least explicit of the four language skills (Vandergrift, 2004). Among multiple scientific methods; surveys, think alouds (immediate retrospective verbalization), and retrospective techniques are the most common ways to explore listening processing problems. In addition, due to recent technological techniques to reveal the process-oriented problems of listeners, tracking online actions (i.e., replaying, rewinding, pausing, forwarding, enabling/disabling subtitles) has been a valuable source for researchers (e.g., Kemp, 2010; Roussel, 2011) to comment on the decisions made by listeners. However, the problems students encounter during listening in pairs in the FL classroom are yet to be studied without 
intervening through think alouds, after-task surveys, or pre-task training sessions, which compromise researchers' ability to observe listening processes and problems naturally in real time.

Thus, this study makes several noteworthy contributions to the available literature by analyzing two valuable data sources which enable the researcher to explore and document the problems listeners encounter. The researcher provided listeners with two options simultaneously by allowing them to both self-regulate (rewind, pause, and fast-forward) the listening input and discuss the task with a peer during listening. Data on the first option was collected via a mouse-tracking program (Morae, 2015) and the second option, was collected via audio and video recorders. Data was organized to classify the problems articulated by students in a peer interactive and self-controlled task. This not only contributes to the available literature on FL listener problems, but also suggests ways to break the vicious cycle of repeating the same methods and problems to create active and interactive listeners in FL listening classrooms.

\section{Literature Review}

Listening comprehension, a key skill for learning and communicating, is considered crucial for target language competence (Morley, 2001). As Morley (2001) states, the change in trends after the second International Association of Applied Linguistics congress in 1969 (Cambridge, UK) was a turning point for the evaluation of this skill in the FL classroom. Researchers emphasized the importance of "individual learners and the individuality of learning; listening and reading as non-passive and very complex receptive processes" (Morley, 2001, p. 69). They cited listening as a fundamental skill in the FL classroom. As a child's very first type of speech activity and the skill that requires the most time and practice, it is a crucial prerequisite for learning 
any language. While listening is vital for learners, it is also considered a very difficult skill for various reasons, stated below.

\section{The Complexity of Listening}

Studies conducted in second and FL learning concur on the difficulty of the skill (Goh, 2000; Hayati, 2010; Vandergrift, 2007). Among various explanations, Graham and Macaro (2008) and Field (2009) identify the source of these challenges as the complexity of listening processes and the necessity of having and using various knowledge sources. Moreover, the "uncontrollable facts" (Graham, 2006, pp. 174-175) of the skill, such as the speed of delivery and accent of the speaker, also create stress for listeners who see themselves as "less skilled in listening than they are in other skills" (Graham \& Macaro, 2008).

\section{FL Listening Problems}

In the available literature, researchers have listed problems encountered by FL listeners from various perspectives. Some have identified problems from a cognitive perspective (Anderson, 2000; Goh, 2000; Vandergrift, 2007), while others have focused on processes involved in listening (Cross, 2010; Goh \& Taib, 2006; Vandergrift \& Tafagodhari, 2010). The first approach categorizes listening problems according to three non-linear and inter-related phases: perception (phonological and lexical problems), parsing (syntactic and semantic problems), and utilization (discoursal and pragmatic problems) (Nowrouzi et al., 2015).

Among those who have categorized comprehension problems under a cognitive schema, Goh (2000) used interviews, diaries, and recall protocols to evaluate the problems of online Chinese listeners according to Anderson's (2000) cognitive model of listening. These problems included, in the perception phase, word recognition, chunking of speech, concentration, and missing the beginning of the text; in the parsing phase, 
forgetting what was heard; and in the utilization phase, understanding the words and intended message of the input.

Similarly, Liu (2002) used interviews, questionnaires, partial transcription, and introspection to identify online processing problems. These problems included unfamiliar vocabulary, sound segmentation, word recognition, and overreliance on phonetic cues.

In order to highlight the individual learners and individuality of learning in FL classrooms, some researchers have added social and affective parameters to better understand listening processes and problems. A study by Rajab and Nimehchisalem (2016) identified the listening comprehension difficulties of Iranian Kurdish listeners based on responses to a questionnaire of beliefs on English language listening comprehension problems (Q-BELLP) (Lotfi, 2012) in the process, input, task, affect, and context categories. They reported that the most common problems related to input, including accent, unclear pronunciation, speech rate, and text length, followed by context, including poor acoustic conditions. Difficulties related to affect and task were emphasized least by the listeners, yet Rajab and Nimehchisalem (2016) stressed they should not be overlooked.

\section{Method}

\section{Research Questions}

This paper examines peer dialogues while performing a listening task. This type of data allowed the researcher to observe the comprehension problems of listeners without interfering with their listening and identify problems not only from an individual aspect but also from a social aspect. In addition, with self-access to input, dialogic exchanges of pairs provided another very valuable source to the researcher in order to understand their needs and problems during listening. Because the current study 
not only documents the cognitive problems articulated by listeners but also witnesses affective and social challenges they experienced, the researcher utilized a more holistic categorization which reflects the richness of this data. The researcher categorized listening difficulties according to the following schema: 1) process related, 2) listener related, 3) affect related, 4) input related, 5) social related, and 6) task related.

Based on this data, the researcher primarily explored the following research questions:

(1) What problems are articulated by A1 level Turkish secondary school students during a peer interactive listening task?

(2) Why do students choose to operate the audio during a peer-interactive listening task?

\section{Participants and Setting}

In this study, students were in the last grade of 12 years compulsory education (4 $+4+4$ ) in Turkey, when students are aged 16-18. They received an estimated 1000+ hours of English instruction till the end of Grade 12 (BC \& TEPAV, 2013, p. 16). 28 students participated and as for gender, 13 were boys, 15 were girls. They were enrolled in two different secondary schools in Istanbul, Turkey.

Students were divided into pairs and given twenty-six minutes to complete a listening comprehension task (see Appendix). The researcher informed all the pairs that they could discuss the task with their peers, and gave pairs a PC to rewind, pause, or fast-forward the audio as much as they wanted. These PCs contained Morae (2015) tracking software which captures on-screen activity and keyboard/mouse input to record students' self-control usage during the task. In order to prevent any interference, each pair was provided a separate room during the task. Each pair was video, and audio recorded. 


\section{Materials}

In this study, the researcher used the "Cambridge English: Key" test (KET) to measure the participants' English listening skills at the onset of data collection. This standardized test is described by the test developers as a proof of someone's ability to use English to communicate in simple situations. It measures skills at the A2 level of the Common European Framework of Reference (CEFR) for reading, writing, listening and speaking. In the current study, only the listening section of the exam was used. This includes 5 listening tasks and 25 listening comprehension questions. The KET test was used to determine the listening proficiency level of the listeners. Anyone with a $70 \%$ or higher achievement is recognized as A2 level in KET. In our case, none of the students recorded a success of $70 \%$ or above, thus considered to be at A1 level accordingly.

Secondly, for the purpose of the study, the researcher designed a listening comprehension task based on an authentic podcast produced by BBC Radio 4. Using the Common European Framework of Reference (CEFR) (2001), the researcher determined the difficulty level of the audio fragment to be B1. At the B1 level, students can understand the gist of radio or TV programs on personal or professional topics when the delivery is relatively slow and clear. The main reason behind choosing a B1 level audio fragment for A1 level learners was to create a task that is challenging enough to uncover as many problems as possible while listening. The audio fragment was 3.5 minutes long and discussed the life of the Egyptian king Ramses II. After listening to the fragment under their different conditions, students were asked to fill out an answer sheet, which was used to measure their comprehension of the fragment. The questions evaluated different levels of listening comprehension. Some dealt with the comprehension of information that was mentioned explicitly (perception, parsing), while others required 
the combination and restructuring of information offered at different points in the text (parsing, utilization) (see Appendix).

\section{Data Coding}

As discussed in the literature review, most studies attempting to classify listening comprehension problems, such as Anderson's (2000) and Goh's (2000), have adopted a cognitive perspective. Following Rajab and Nimechisalem (2016), the researcher categorized the students' listening comprehension problems under process-, listener-, affect-, input-, and task- related categories and added another category of “social-" (Table 1).

Table 1. Problem categories and subcategories

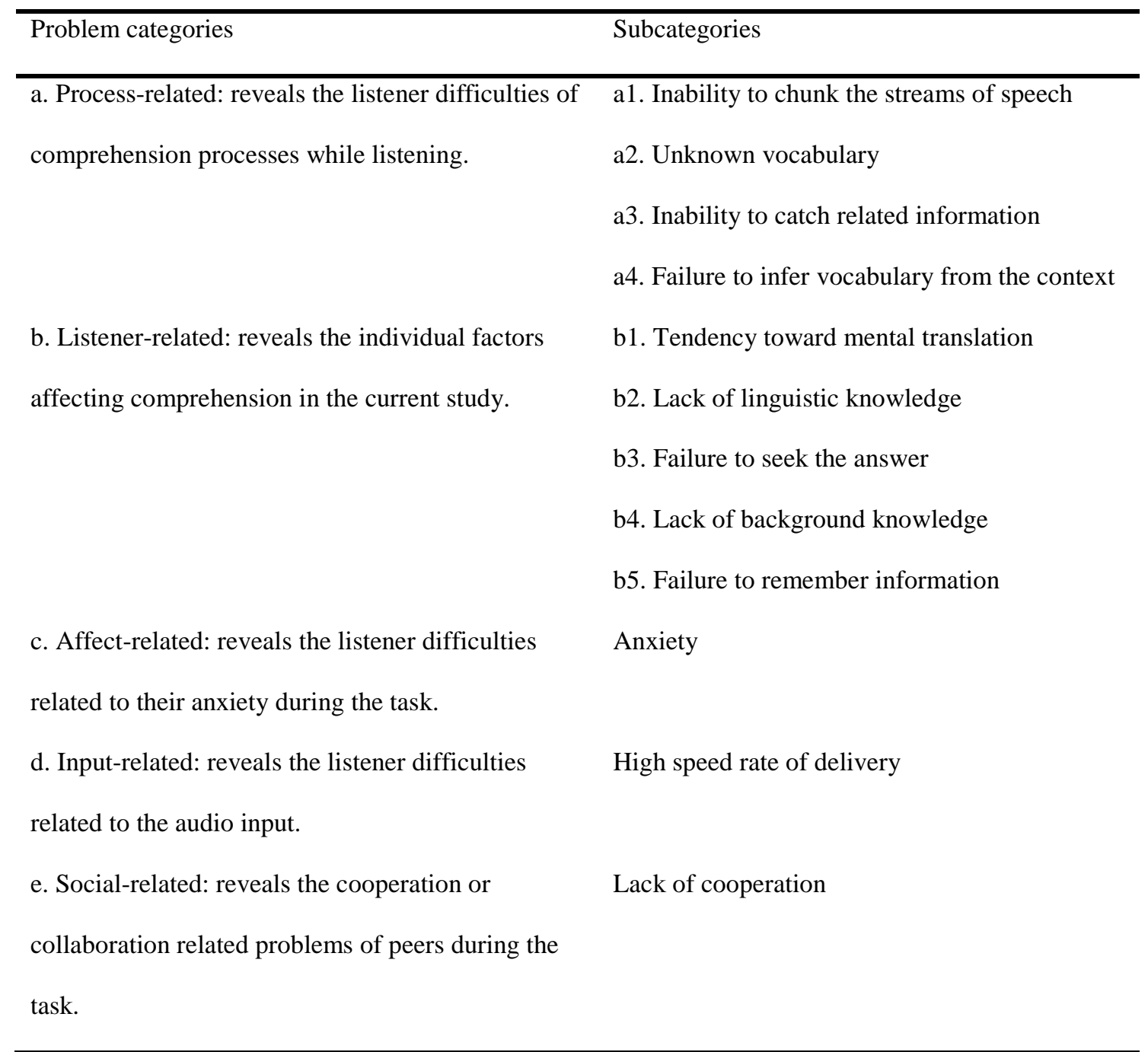


f. Task-related: reveals the difficulties of listeners Lack of task knowledge resulted from task demands.

Problems were identified as occurring at a high (66-100\%), moderate (34-65\%), or low (1-33\%) rate (interrater reliability was 0.93$)$.

\section{Results}

\section{Pair Dialogues}

The researcher concluded that students experienced a high rate of process-, listener- and input- related problems and a moderate rate of affect-, social-, and taskrelated problems during the task (Table 2).

Table 2 Categories and rates of the problems

\begin{tabular}{lll}
\hline Problem categories & Subcategories & Rates \\
\hline a. Process-related & a1. Inability to chunk the streams of speech & High \\
& a2. Unknown vocabulary & Moderate \\
& a3. Inability to catch related information & High \\
& a4. Failure to infer vocabulary from the context & Moderate \\
b. Listener-related & b1. Tendency toward mental translation & High \\
& b2. Lack of linguistic knowledge & Low \\
& b3. Failure to seek the answer & Low \\
& b4. Lack of background knowledge & Moderate \\
& b5. Failure to remember information & Low \\
c. Affect-related & Anxiety & Moderate \\
d. Input-related & High speed rate of delivery & High \\
\hline & Lack of cooperation & Moderate \\
& & Moderate
\end{tabular}


a) Process-related problems. This category reveals the listener difficulties of comprehension processes while listening. Process-related problems, the most frequent category of difficulty expressed during peer interaction, occurred for various reasons.

a1) Inability to chunk the streams of speech. In every pair dialogue, students expressed difficulty streaming the speech while listening (100\%). Students' statements were similar to Anderson's (2000) reports. For example, one pair said, "It was too long to understand and relate the item to the information!" (Sena and Merve).

a2) Unknown vocabulary. Many students said that they did not know some of the words in the stream. The problem occurred at a moderate rate $(44 \%)$ in the study. One pair stated, "I do not know what prosperous means" (Eda and Selin). Another said, "In charge of, in charge of... What does that mean?!" (Recep and Sude).

a3) Inability to catch related information. Some students reported that they were unable to catch related information while listening. This problem occurred at a moderate rate (42\%). During these dialogues, students questioned the information needed for the related question (e.g., "Did you hear anything related to Item 4?" [Buse and Serap]; "How many times did he say England? [Omer and Seda]; "Those vocabulary words were not in the stream, were they?" [Ayse and Ozgur]; and "Did you hear anything about those dates?" [Engin and Hilal]).

a4) Inability to infer the meaning of words. Difficulties inferring vocabulary occurred at a low rate (19\%). Students expressed their confusion in different ways, such as "I could not understand the word and the context in which it was used!" (Buse and Serap) or "Unscrupulous must be a kind of adjective, but ... what did he mean by saying he was unscrupulous at that?" (Sena and Merve). 
b) Listener-related problems. This category reveals the individual factors affecting comprehension in the current study. The researcher defined listener-related problems in accordance with Brindley and Slatyer (2002, p. 375).

b1) Mental translation. Many students experienced comprehension problems because of their tendency to translate every word without discerning the key message of the speaker. This problem occurred at a very high rate (100\%). One student asked, "He had great gardens, harvest... what does that mean? I think harvest is like something about agriculture, so he had... I don't know. It already passed!" (Gokhan and Kubra). Another said, "Self-publicist... Public... I think it is like republic, like Republic of China?" (Sermin and Goktug).

b2) Linguistic knowledge. In a low percentage (14\%) of peer dialogues, students expressed grammar and/or spelling problems during listening (e.g., "We need to correct the false ones. So, 'It wasn't a tomb'... No wait! Wasn't or isn't?" [Cetin and Seda]; "Write it down, wives... wait! Wife is wife, but wives? Like in the ocean or what?" [Sena and Merve]).

b3) Failure to seek the answer. Some students ended the conversation before deciding on an answer to a question. This type of problem occurred at a low rate (10\%). Example statements include, "Ok, next one is self-publicist... Let's leave it, no idea. Ok, anyways" (Kenan and Idil) and "What about 14? How can we answer it? Selfpublicist... We cannot [laughing]! All right!" (Nil and Oguz).

b4) Lack of background knowledge. Problems related to a lack of the necessary background knowledge occurred at a moderate rate (45\%). Students asked each other, "What do we need to write for that one? It is asking about Ramses. Have we heard about it in English lessons? Is it a worshipping tomb or what?" (Ege and Emin) and 
"Which one is the Ramses according to the definition in the audio... Which one do you think? I have totally no idea about it. I have not heard about him in my life."

b5) Failure to remember information. A low number of students (28\%) encountered difficulty remembering information in the audio (e.g., "This is about 'selfpublicist,' did you hear that? Yes, but I do not remember what he said" [Ekrem and Busra] and "I don't even know one of these words. I heard him saying prodigious, but I don't remember its context" [Hale and Erdem]).

c) Affect-related problems. Some students expressed anxiety while performing the task. This problem occurred at a moderate rate (41\%). One student stated, "Oh my! Last two minutes! Easy! It is not an exam! I don't feel like doing it!... What about that one? I only know well that I am very bad at English and cannot do anything more about those now" (Selin and Recep).

d) Input-related problems. Many students verbalized difficulty keeping pace with the speed of the input. This problem occurred at a high rate (74\%). Some example statements include, "I was just trying to get what he meant when suddenly he moved on to another thing, and before I could understand it was all over!" (Tugce and Salih) and "He was too fast to be understood! I was waiting for anything related to a self-publicist, then I realized that the audio was over!" (Cetin and Selma).

e) Social-related problems. A moderate number (37\%) of pairs had difficulty cooperating because of differing opinions on questions, answers, audio, or selfcontrolling the input during the task. One pair said, "Let's write about a self-publicist. It is good... No! it is not good; it is something else. I think it means patriot or something. I don't agree!" (Celik and Gulus). Another argued, "How did you decide on seven? I heard something; I am not sure. Why are you erasing? I don't think it is true" (Vedat and Jale). 
f) Task-related problems. A moderate number of dialogues (45\%) revealed that students were unsure of how to perform the task (e.g., "Multiple vision... Are all those questions related to the same audio?" [Selin and Ege] and "Translate these words... Are they asking to give meanings or what? According to the passage? I do not understand that!" [Kenan and Lale]).

\section{Self-regulation of the Input}

The researcher defines self-regulation as the autonomy to exercise the physical control over listening input. In this study, students collaborated on the type and timing of the actions (rewind, pause, and fast-forward) and duration of pauses during discussions. They regulated the audio primarily to rewind (60\%), then to pause (30\%), and lastly to forward (10\%) while listening.

As for the reasons of actions, pairs mainly used the audio control option to keep pace with the speed of delivery (83\%), to find relevant information $(74 \%)$, to check for understanding (73\%), to cooperate with a peer (66\%), to infer the meaning of a word (18\%). In these instances, self-regulation fostered resolution and collaboration during the task. In order to exemplify how self-regulation affects comprehension and collaboration during a listening task, the researcher chose relevant examples from the data of pairs $(\mathrm{N}=28)$ with this option (Table 3). Students used the audio controls to address $66 \%$ of their problems during listening.

Table 3 Reasons, frequency and examples of self-regulation of the input

\begin{tabular}{lll}
\hline Reasons & Frequency & Examples \\
\hline to keep pace with the speed of & $83 \%$ & "What does he say? Saved time and something... It was \\
delivery & & way too fast! OK, let's rewind!" (Ece and Fetih) \\
to find relevant information & $74 \%$ & "What about gods? In his tomb or what? Hmm, we need \\
& & to listen again to find it!" (Bilge and Sude)
\end{tabular}




\begin{tabular}{|c|c|c|}
\hline to check for understanding & $73 \%$ & $\begin{array}{l}\text { "I think he said, 'to save time and money.' Not sure... } \\
\text { Let's rewind a little!"(Mine and Selman) }\end{array}$ \\
\hline to cooperate with a peer & $66 \%$ & $\begin{array}{l}\text { "He had a hundred children. Did it say so? Yes, look, } \\
\text { listen now!" (Muge and Bekir) }\end{array}$ \\
\hline to infer the meaning of a & $18 \%$ & "What is replicate? Rewind a little, it says replicated \\
\hline word & & again and again... " (Sefa and Kayra) \\
\hline
\end{tabular}

\section{Discussion}

The students' dialogic interactions enabled the researcher to diagnose the types of difficulties of A1 level Turkish $(\mathrm{N}=28)$ secondary school students encountered while performing a peer interactive and self-regulated listening task. Analysis revealed thirteen listening comprehension problems related to six different categories (Lotfi, 2012). Four of those problems were related to process, five to the listener, and one each to affect, input, social dynamics, and the task.

Process- and listener-related factors accounted for the majority of problems. This result may be a consequence of the fact that listeners have to address complex processing demands while simultaneously activating needed skills as a listener, demonstrating the convergence of these two categories. Chunking the streams of speech arose as a problem at a high rate that was experienced by all the pairs at least once (100\%) which could be a result of their grade level (A1) and/or the comprehension gap between the grade level (A1) and the level of the task (B1). Likewise, the listenerrelated problem of mental translation occurred in every pair dialogue (100\%). In the literature, both of these problems are defined as lower-level processing issues and are associated with a low proficiency level (Goh, 2000; Hasan, 2000). In the current study, students had a tendency to mentally translate unknown units of information, which might be a reason for and result of inability to chunk the streams of speech. This 
tendency obscures the general idea of the input and deserves attention in teaching FL listening.

Failure to remember information as a consequence of short-term memory capacity, plays an important role in listening tasks due to its vital role to maintain and manipulate the information accordingly and increases the difficulty of listening comprehension for lower level listeners (Xu, 2008). However, in this study, it occurred at a low rate. Besides obscuring the general idea, focusing on smaller units more than general ones while listening, also causes missing information and thus remembering information is expected to become even more challenging for A1 level listeners. According to Vandergrift and Goh (2012), remembering information is expected to remain one of the major problems which shows the 'cognitively demanding' nature of the skill in terms of memory. When linked to previously mentioned lower processing problems, its occurring at a low rate might prove another positive effect of selfregulating the input while listening as it corresponds with the three main reasons of listeners' self-regulation in the study; 1) to keep pace with the speed of delivery, 2) to find relevant information and, 3) to check for understanding.

One of the remaining listener-related problems, a lack of background knowledge (45\%), is also an important factor in processing the input (Anderson, 2000). In the current study, listeners expressed their lack of prior knowledge about Ramses II, which may have resulted in an inability to interpret inferences while listening (Goh, 2000). This tendency could be connected to mental translation (100\%) of the information in the data, which corresponds with a lower-level processing of the input (Call, 1985).

While found to be a major problem in other studies, linguistic problems of grammar and/or spelling occurred only at a low rate (14\%) in the current study. Listeners with the option to control the audio did not use the option to address those 
problems. Among various explanations, the researcher posits that, instead of focusing on the functions of the vocabulary, students focused on understanding the meaning of unknown vocabulary (44\%) in the text. This is another piece of evidence that listeners worked on higher level processes than the perception of those units and lack of vocabulary is a listening comprehension obstacle to most students (Underwood, 1989).

In addition, it is obvious in this study that the speed of delivery and catching related information maintained their significance among other problems. This finding corresponds with the studies done by Flowerdew and Miller (1992) and Hayati (2010), who have reported that the speed of delivery as one of the greatest obstacles to understanding while listening. Frequent use of the audio control to keep pace with the speed of delivery $(83 \%)$, a problem that occurred at a high rate $(74 \%)$, strengthens theories that a high-speed rate of delivery is one of the major problems for FL listeners (Goh,1999; Hamouda, 2012; Hayati, 2010; Underwood, 1989).

Prior experience with the demands which are required to perform a particular task is another relevant factor in listening comprehension. In this study, students were not familiar with neither peer interactive nor self-regulated listening tasks in their FL classes. A moderate number of students (34\%) expressed difficulty with elements of the task, including "task procedures, such as the nature of the task instructions and the number of times listening, and task response characteristics, such as the item type or the length and complexity of the required response" (Vandergrift, 2007, pp. 191-210) and the vocabulary level of the task. This finding underlines the importance of task familiarity in FL listening. Thus, as Vandergrift (2002) suggests, teachers can ask students to perform various tasks in order to foster extensive listening. Vandergrift and Goh (2012) exemplify this by defining two types of tasks, first; one-way listening tasks, when the listener is not an active participant of a face-to-face interaction. Second type is 
interactive listening tasks, in which the listener is an active participant of a real-time communication. By diversifying tasks, teachers may provide opportunities for listeners to develop essential listening skills and to improve recognition of sounds and to make use of their background knowledge to promote comprehension.

As stated in the literature, listening is a psychological process as well as a cognitive one. Feeling nervous or anxious might hinder concentration and thus comprehension (Yagang, 1993). In the current study, despite the workload of the task, students' levels of anxiety were moderate. Self-regulating the input might have had a positive effect on this factor. In terms of anxiety, there is convincing evidence that people who take initiative in learning (proactive learners) are more purposeful and have greater motivation (Knowles, 1975). The researcher found self-regulation usage for the total problems to be $66 \%$. This result indicates that controlling the input eases the heavy workload of addressing comprehension problems while synchronizing with the flow of the input. This observation corresponds with Wang's (2010) plausible reasoning of the pitfalls of a teacher-controlled listening task, in which students have little control of the learning process. In this study, leaving questions unanswered or failure to seek the answer to a question occurred least frequently (10\%), which illustrates effort and involvement of the students while listening with a peer.

Lastly, social related problems also caught attention as they occurred at a moderate level. Primary cooperation problems were different opinions on questions, answers, or self-controlling the input during the task. When the available literature is considered, collaboration is a crucial element of the possible gains of peer interaction in a language classroom (Storch, 2002). The role peers admit (i.e., dominant or passive) is also an important factor in collaborating, which is beyond the scope of this paper. However, in this study, the self-regulation usage for cooperation problems (66\%) 
showed that students paid considerable attention on those cooperation problems during the task.

\section{Limitations of the Study and Suggestions for Further Research}

There are some limitations of the current study. Firstly, it was conducted in a specific country and the sample size was relatively small $(\mathrm{N}=28)$. Secondly, it reports the observations of a single listening task. Thirdly, due to the practical reasons, the students who participated in the study were not selected randomly, they performed the task in their intact classes instead.

To further investigate the questions explored in this paper, researchers may utilize different methodologies, such as integrating self-awareness (cognitive) training for listeners to better understand differences in listening skills, creating collaborative communication expectations and teaching students how to be more collaborative, or conducting a longitudinal study that includes various listening tasks. Also, connecting students' cognitive comprehension levels with the comprehension level of the assigned listening tasks may be considered. These methods may present a clearer representation of the problems faced by listeners in FL classrooms.

\section{Conclusion}

By discussing six categories of listening difficulties, the researcher hoped to better explain the different factors that comprise success in listening comprehension, and thus, the critical areas to focus on in order to ease the heavy workload of a listener. Taken together, these skills lie at the heart of communication (Vandergrift, 2002) and are very complex to acquire. Any endeavor by researchers to diagnose FL listening problems might help practitioners engage in more holistic approaches in FL classrooms. Because the skills needed for listening are a very strong indicator of other skills, such as reading, speaking, and writing, an FL learner's potential as a listener influences 
communicative and educative gains.

The current study makes notable contributions to the FL listening literature by highlighting the possible benefits of peer interaction and self-regulation of the audio on the listening comprehension problems of A1 level listeners. People who take the initiative in learning (proactive learners) absorb more material than do people who sit at the feet of teachers, passively waiting to be taught (reactive learners), because they approach learning more purposefully (Knowles, 1975). Thus, the more active and interactive an FL learner is, the more enthusiastic and able he or she is to experience the global demands of learning a foreign language. 
References

Anderson, J. (2000). Cognitive psychology and its implications (5th ed.). New York, NY: Worth.

Brindley, G., \& Slatyer, H. (2002). Exploring task difficulty in ESL listening assessment. Language Testing, 19, 369-394. doi:10.1191/02655322021t236oa

British Council \& TEPAV. (2013, November). Turkey national needs assessment of state school English language teaching. Retrieved from https://www.britishcouncil.org.tr/sites/default/files/turkey_national_needs_asses sment_of_state_school_english_language_teaching.pdf

Call, M. (1985). Auditory Short-Term Memory, Listening Comprehension, and the Input Hypothesis. TESOL Quarterly, 19, 765-781. doi:10.2307/3586675

Council of Europe (2001): Common European Framework of Reference for Languages: learning, teaching, assessment. Cambridge, UK: Cambridge University Press.

Cross, I. (2010). Listening as covert performance. Journal of the Royal Musical Association, 135, 67-77. doi:10.1080/02690400903414848

Field, J. (2009). Listening in the Language Classroom. Cambridge, UK: Cambridge University Press. doi:10.1017/CBO9780511575945

Flowerdew, J., \& Miller, L. (1992). Student perceptions, problems and strategies in second language lecture comprehension. RELC Journal, 23, 60-80. doi:10.1177/003368829202300205

Goh, C. (1999). How Much do Learners Know about the Factors that Influence their Listening Comprehension? Hong Kong Journal of Applied Linguistics, 4, 17-42. Retrieved from http://caes.hku.hk/hkjalonline/issues/download_the_file.php?f=1999_v4_1_goh. pdf 
Goh, C. (2000). A cognitive perspective on language learners' listening comprehension problems. System, 28, 55-75. doi:10.1016/S0346-251X(99)00060-3

Goh, C., \& Taib, Y. (2006). Metacognitive instruction in listening for young learners. ELT Journal, 60, 222-232. doi:10.1093/elt/cc1002

Graham, S. (2006). Listening comprehension: The learners' perspective. System, 34, 165-182. doi:10.1016/j.system.2005.11.001

Graham, S., \& Macaro, E. (2008). Strategy instruction in listening for lowerintermediate learners of French. Language Learning, 58, 747-783. doi:10.1111/j.1467-9922.2008.00478.x

Hamouda, A. (2012). Listening comprehension problems - Voices from the classroom. Language in India, 12, 1-49. Retrieved from: http://www.languageinindia.com/aug2012/v12i8aug2012.pdf

Hasan, A. S. (2000). Learners' perceptions of listening comprehension problems. Language Culture and Curriculum, 13, 137-153. doi:10.1080/07908310008666595

Hayati, A. (2010). The effect of speech rate on listening comprehension of EFL learners. Creative Education, 1, 107. doi:10.4236/ce.2010.12016

Kemp, J. (2010). The listening log: motivating autonomous learning. ELT journal, 64, 385-395. doi:10.1093/elt/ccp099

Knowles, M. S. (1975). Self-Directed Learning: A Guide for Learners and Teachers. New York, NY: Association Press. doi:10.1177/105960117700200220

Liu, N. F. (2002). Processing Problems in L2 Listening Comprehension of University Students in Hong Kong (Doctoral dissertation). Retrieved from http://hdl.handle.net/10397/2718 
Lotfi, G. (2012). A questionnaire of beliefs on English language listening comprehension problems: Development and validation. World Applied Sciences Journal, 16, 508-515. Retrieved from https://pdfs.semanticscholar.org/fe11/fab693e27751e12be532c9e981c4f609f841 .pdf

Morae [Computer software]. (2015). Retrieved from http://www.techsmith.com/morae.html

Morley, J. (2001). Aural comprehension instruction: Principles and practices. In M. Celce-Murcia (Ed.), Teaching English as a Second or Foreign Language (3rd ed., pp. 69-85). Boston, MA: Heinle \& Heinle Publishers.

Nowrouzi, S., Tam, S. S., Zareian, G., \& Nimehchisalem, V. (2015). Iranian EFL students' listening comprehension problems. Theory and Practice in Language Studies, 5, 263-269. doi:10.17507/tpls.0502.05

Rajab, S. Y., \& Nimehchisalem, V. (2016). Listening comprehension problems and strategies among Kurdish EFL learners. The Iranian EFL Journal, 12, 6-27. Retrieved from https://www.elejournals.com/iranian-efl/the-iranian-efl-journalvolume-12-issue-4-december-2016

Roussel, S. (2011). A computer assisted method to track listening strategies in second language learning. ReCALL, 23, 98-116. doi:10.1017/S0958344011000036

Storch, N. (2002). Patterns of interaction in ESL pair work. Language Learning, 52, 119-158. doi:10.1111/1467-9922.00179

Underwood, M. (1989). Teaching Listening. New York, NY: Longman.

Vandergrift, L. (2002). It was nice to see that our predictions were right: Developing metacognition in L2 listening comprehension. Canadian Modern Language Review, 58, 555-575. doi:10.3138/cmlr.58.4.555 
Vandergrift, L. (2004). Listening to Learn or Learning to Listen? Annual Review of Applied Linguistics, 24, 3-25. doi:10.1017/S0267190504000017

Vandergrift, L. (2007). Recent developments in second and foreign language listening comprehension research. Language Teaching, 40, 191-210. doi:10.1017/S0261444807004338

Vandergrift, L., \& Goh, C. (2012). Teaching and Learning Second Language Listening: Metacognition in Action. New York, NY: Routledge. doi: $10.4324 / 9780203843376$

Vandergrift, L., \& Tafaghodtari, H. M. (2010). Teaching L2 learners how to listen does make a difference: An empirical study. Language Learning, 60, 470-497. doi:10.1111/j.1467-9922.2009.00559.x

Wang, Y. (2010). To give control to learners or not? A comparative study of two ways of teaching listening. English Language Teaching, 3, 162-174. doi:10.5539/elt.v3n2p162

Xu, F. (2008). Short-term memory in EFL listening comprehension. Asian Social Science, 4. 103-107. doi:10.5539/ass.v4n4p103

Yagang, F. (1993). Listening: Problems and solutions. English Teaching Forum, 31, 16-19. Retrieved from: https://valrc.org/courses/esolbasics/lesson5/docs/Listening_a.pdf 
Appendix

Ramses II Comprehension Questions

A. Which of the statements below are true (circle the ones that are correct)?

1. A. Ramses II was in charge of Egypt for 86 years.

2. B. During the reign of Ramses, Egypt was very rich.

3. C. Ramses II built many monuments.

4. D. Ramses II lived in the time of Cleopatra.

B. There are three reasons why Ramses II is considered "lucky". Circle the three reasons that are mentioned.

1. Ramses lived to be almost 90 years old --- 2. He had a great garden that produced amazing harvests --- 3. He had nearly 100 children --- 4. He lived to be more than 90 years old ---5. The Nile didn't flood during his reign - 6. He had nearly 100 wives --- 7. Egypt was blessed with great harvests during his reign.

C. Why is Ramses II called a self-publicist? Please briefly explain and give ONE example.

D. Choose the picture of the Abu Simbel according to the description in the lecture.
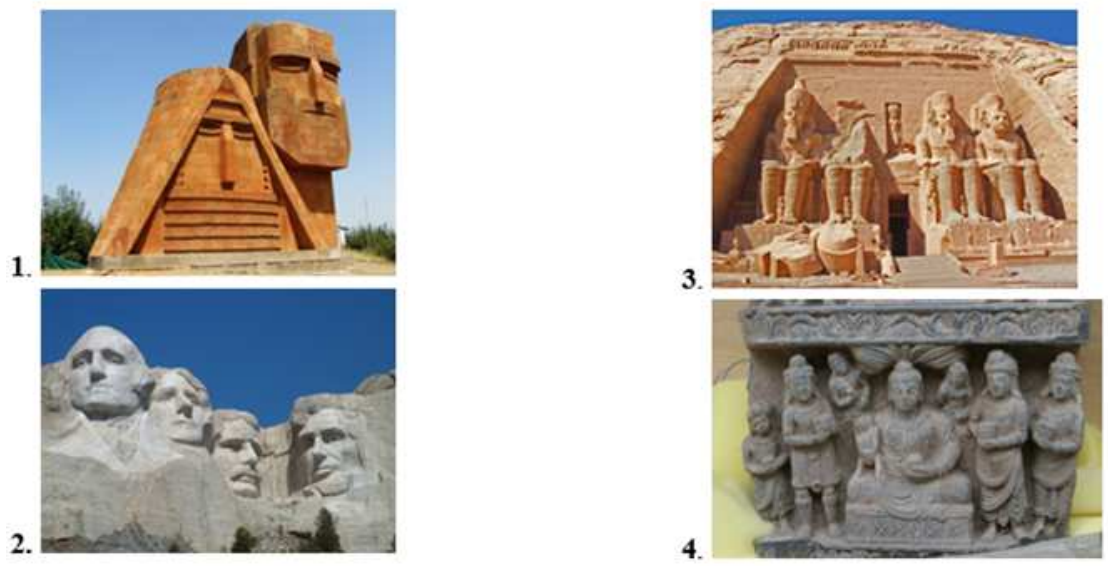
E. Are the following statements about the Ramesseum True (T) or False (F)? Correct the False ones.

..... 1. The Ramesseum is as big as a football pitches.

.... 2. The Ramesseum is a temple where Ramses worshipped his gods.

..... 3. The Ramesseum is a tomb where Ramesses II was buried.

..... 4. The Ramesseum in near Luxor.

F. Translate the following English words into Turkish as they are used in the audio

1. Colossal

2. Unscrupulous :

3. Venerate

4. Replicate

G. What does Antony Gormley mean with the 'waiting quality of the sculptures'?

\section{Thank you!}

